\title{
A abordagem de temas sensíveis em curtas-documentário: reflexões sobre os usos do passado ${ }^{1}$
}

\author{
Approaching Sensitive Issues in Short \\ Documentaries: Reflections on Uses of the Past
}

\author{
Marcelo Henrique Leite* \\ Rafael Monteiro de Oliveira Cintra**
}

\section{RESUMO}

$\mathrm{O}$ presente artigo tem o objetivo de apresentar uma contribuição acerca da construção de temas sensíveis no ensino de História. Tomamos como objeto da nossa reflexão um conjunto de curtas-metragens produzidos por estudantes do Ensino Médio de uma escola localizada na cidade de Itu-São Paulo. No primeiro momento, relacionamos as pesquisas documentais que precedem à criação dos curtas com as discussões sobre história do tempo presente. No segundo momento, elaboramos uma análise dos curtas a partir das discussões da temporalidade históricas e da perspectiva da criação fílmica como modo de evidenciar uma sociedade fraturada e, ao mesmo tempo, sugerir uma nova partilha do sensível.

Palavras-chave: ensino de História; tempo presente; temas sensíveis.

\begin{abstract}
The aim of this article is to introduce some contributions on the construction of sensitive issues in History teaching. Our reflection focuses on a group of short films produced by High School students who attend a school in Itu-São Paulo. At first, we relate the documental research which anticipates the production of such short films to the debates concerning a History of the Present Time. Then, we elaborate on the analysis of those short films from the viewpoint of historical temporalities as well as the perspective of filmic creation as it evidences a fractured society and, at the same time, proposes a new sharing of the sensitive.

Keywords: History teaching; presente time; sensitive issues.
\end{abstract}

\footnotetext{
* Universidade Federal do Estado do Rio de Janeiro (UNIRIO), Rio de Janeiro, RJ, Brasil. marcelo. leite23@gmail.com

** Universidade do Estado do Rio de Janeiro (UERJ), Rio de Janeiro, RJ, Brasil. errimonte@gmail. com
} 
Dos muitos desafios do ensino de História, reconhecer o presente como parte fundamental da/na aprendizagem é um deles. Sendo assim, este artigo toma um projeto de cinema estudantil como objeto de análise no campo do ensino de História. Projeto que, desde 2016, ocorre com alunos do Ensino Médio de uma escola do estado de São Paulo, envolvendo as disciplinas de História e Língua Portuguesa. A análise articulará alguns pressupostos da Teoria da História, da Filosofia e da Educação. O artigo está organizado de acordo com as quatro etapas do projeto de cinema estudantil, que são: anúncio de um tema aos alunos, produção de uma pesquisa por parte deles, elaboração dos curtas-metragem e realização de um festival. Logo, o artigo percorrerá este caminho: analisar os temas, as pesquisas e os curtas.

A conviç̧ão de que os adolescentes são sujeitos de sua própria história une o professor Marcelo (História) e a professora Claire (Língua Portuguesa) na elaboração de um projeto transdisciplinar no qual a tônica é o estímulo à autonomia intelectual dos alunos do Ensino Médio: O Festival Estudantil de Curtas (FEC). ${ }^{2}$ A proposta central é a criação de um espaço pedagógico para que alunos possam expressar suas visões de mundo por meio da linguagem audiovisual, produzindo, a partir de um tema gerador, curtas-metragem que dialogam com o cinema documentário e, portanto, a partir de agora os chamaremos de curtas-documentário.

O FEC é desenvolvido desde 2016, sendo parte da cultura escolar. Ele é um instrumento avaliativo nas disciplinas proponentes e ocorre ao longo de seis meses, objetivando, sumariamente, o desenvolvimento de habilidades. $\mathrm{O}$ início do projeto se dá quando os professores anunciam o tema anual. $\mathrm{Na}$ mesma oportunidade, cada turma é dividida em grupos de trabalho com 4, 5 ou 6 componentes, cuja tarefa inicial é discutir e delimitar uma abordagem do tema. Duas semanas depois, os dois professores, em sala de aula, ouvem as abordagens escolhidas e então comentam e orientam os grupos quanto a dificuldades de pesquisa e produção ou apontando novas possibilidades.

Após essa etapa inicial, os alunos têm, em média, dois meses para fundamentar um caderno de pesquisa autoral, que deve ser composto por indicação de referências bibliográficas, orientações metodológicas por parte dos professores, entrevistas, visitas a museus, consulta a acervos históricos, leitura e interpretação de composições musicais e textos literários. Com linguagem científica e obedecendo às normas da ABNT, eles elaboram cadernos de pesquisa, 
que são amplamente debatidos em sala de aula, com devolutivas e sugestões relacionadas tanto ao conteúdo quanto ao processo de escrita.

Após as devolutivas sobre pesquisa, os grupos dão início ao processo da produção de um curta-documentário. São oferecidas oficinas optativas no contraturno escolar ou aos fins de semana para o desenvolvimento de habilidades do universo audiovisual como, por exemplo, aulas de edição, filmagem, trilha sonora, e sobre as características de um documentário. São cerca de dois meses de produção.

Após enviados, os professores avaliam os filmes e em seguida os disponibilizam na página do Youtube do projeto. Neste momento, as produções são submetidas a uma avaliação externa de jurados - profissionais das áreas de Educação, Cinema, História e Linguagens, escolhidas pelos professores orientadores. É aproximadamente um mês para todo esse processo final até a premiação. Na semana da premiação, todos os curtas são exibidos para a comunidade escolar, quando seus criadores podem responder a questões, comentários e apresentar a trajetória de produção dos filmes. O momento da premiação ocorre à noite e todos os curtas têm a possibilidade de serem premiados em diferentes categorias.

Até o presente momento, o FEC possui quatro edições concluídas. Os professores, anualmente, elegem um tema, que é anunciado a todas as séries do Ensino Médio conjuntamente. Em 2016, o tema foi "Direito à memória histórica”; em 2017, "Que história conta nossa casa?”; em 2018, "Histórias na ponta da língua" e, em 2019, "Se a história fosse nossa...”. Percebe-se que alguns curtas surgem como forma de cumprir o tema proposto: ${ }^{3}$ cultura material e arquitetura ( 9 curtas), enquadrados quando o tema central jogava luz à casa, ou mesmo o caso da abordagem de manifestações linguísticas (4 curtas), em que a proposta foi discutir a relação entre História e a Língua Portuguesa na edição de 2018. O nosso foco de análise são os curtas que mobilizam temáticas que transcendem ao tema central e imprimem um olhar que articula a relação entre passado e presente de modo a enfrentar questões postas em nosso tempo. São esses: patrimônio e memória, presentes em 12 curtas; relações étnicos-raciais, 7 curtas; e as questões de gênero, 4. As produções citadas representam quase $50 \%$ de todo o conjunto mapeado, sendo, portanto, uma marca incontornável desse projeto.

Elencamos, para esta análise, um curta que representa cada categoria, pois 
desta forma podemos articular melhor as discussões que proporemos. O curta Marcados (2019) ${ }^{4}$ foi o escolhido na categoria de Patrimônio e Memória, por discutir um tema englobado nas discussões sobre patrimônio difícil, ${ }^{5}$ por tratar-se do hospital-colônia para pessoas com hanseníase, O Hospital Dr. Francisco Ribeiro Arantes, mais conhecido como Pirapitingui, tombado pelo Conselho de Defesa do Patrimônio Histórico, Arqueológico, Artístico e Turístico (CONDEPHAT). Olha quem fala! $(2018)^{6}$ representa os curtas que enfrentam as questões de gênero, pois no centro de sua narrativa está a desvalorização do discurso feminino, incluindo um trecho de Marielle Franco na tribuna. Nas relações étnico-raciais, Trabalhadores, a invisibilidade urbana $(2019)^{7}$ agrega as discussões de outros curtas desta categoria, ao representar o trabalho de varredores de ruas e catadores de lixo em interface com permanências advindas da escravidão.

Nossa proposta, neste artigo, é enfrentar um elemento central para as discussões na área de pesquisa em ensino de História: a construção de temas sensíveis como forma de articular o passado pelos alunos. Fernando Seffner e Nilton Mullet Pereira (2018) operam com essa categoria relacionando-a a passados vivos e questões sensíveis. Os autores argumentam que o enfrentamento de resíduos do passado no presente deve ser pensado também pela ampliação das discussões em torno de educação e direitos humanos, seja na ordem internacional, com a ONU, seja no âmbito nacional, amparado na Constituição de 1988.

Supor um passado vivo implica pensar duas urgências que se apresentam hoje ao ensino de história: as questões sensíveis e a diferença. As questões sensíveis nos deslocam e nos colocam no lugar de alguém que aborda o presente ao mesmo tempo que pensa o passado. São questões que nos levam a discutir o pertencimento e a necessidade que os jovens têm de se reconhecer numa história determinada, de olhar para si mesmos e se autoafirmarem. (SEFFNER e PEREIRA, 2018, p. 20, grifo nosso)

Carmem Gil e Jonas Eugenio (2018) buscam outras referências para discutir temas sensíveis, pensando-os como controversos, sendo importantes na formação do professor de História. Os autores tomam os temas sensíveis como "questões vivas para a sociedade, controvérsias na historiografia, temas 
constrangedores para determinados grupos sociais, difíceis no contexto da escola" (GIL e EUGENIO, 2018, p. 141). Há algo similar entre o que escrevem Gil e Eugenio e aquilo que é proposto por Seffner e Pereira: a questão identitária e a necessidade do enfrentamento, em linhas gerais, da persistência das violências.

Faremos essa discussão em dois momentos. No primeiro, pensaremos as produções em diálogo com os estudos da História do Tempo Presente. No segundo, buscaremos refletir sobre a criação estudantil dos curtas no diálogo com o mundo e possibilidades outras de existir.

\section{O PRESENTE COMO UMA QUESTÃO PARA O ENSINO DE HISTÓRIA}

Dos vários caminhos possíveis para uma discussão sobre os usos do passado pelos alunos na concepção dos curtas, o que escolhemos trilhar nessa seção é pensá-los por meio de três autores: François Dosse (2015), Andreas Huyssen (2000) e Henry Rousso (2016). Entendemos que os temas sensíveis no ensino de História se fortalecem como uma categoria importante para as pesquisas quando aliadas aos estudos da História do tempo presente. Sendo assim, as noções de "o não contemporâneo no contemporâneo" de Dosse, “passados não encerrados" de Rousso e "passados presentes" de Huyssen são elementos centrais em nossa discussão.

Primeiro, cabe analisarmos trechos retirados das pesquisas científicas ${ }^{8}$ realizadas pelos grupos dos três curtas. Vejamos as justificativas:

[Olha quem fala! (2018)] [...] nós, mulheres, mesmo ao alcançarmos cargos de poder e respeito, estamos sujeitas a ter nosso discurso menosprezado diariamente, tanto em espaços privados quanto em espaços públicos. Nosso objetivo com este caderno de pesquisa e com o curta-metragem não é apenas dar um parâmetro de como, há séculos, mulheres são reprimidas por seus discursos ou silenciadas para não poderem proferi-lo, mas, principalmente, mostrar como, desde os anos 1800, o movimento feminino vem se articulando fortemente para combater esse tipo de machismo. (Produção estudantil, grifo nosso)

[Marcados (2019)] O que hoje é o Hospital Dr. Francisco Ribeiro Arantes, já foi conhecido no passado por Asilo-Colônia do Pirapitingui, um dos maiores hospitais de tratamento de hanseníase do Brasil e também o tema de nosso trabalho. Nesse 
(sic) caderno de pesquisa buscamos abordar as histórias abandonadas no hospital, pois se essa história fosse nossa, gostaríamos que todos soubessem quem viveu e o que aconteceu por lá. [...] Com isso buscamos descobrir mais sobre essa história que foi tão apagada dos anais da história oficial da cidade de Itu. (Produção estudantil, grifo nosso)

[Trabalhadores, a invisibilidade urbana (2019)] O tema escolhido por nosso grupo para o Festival Estudantil de Curtas de 2019 foi "Os trabalhadores urbanos". Nesta pesquisa, pretendemos estabelecer uma relação entre os escravos mantidos pelo Estado brasileiro durante os períodos colonial e imperial e os trabalhadores urbanos atuais que agem principalmente na manutenção da cidade de Itu. [...] Pretendemos, então, explorar a história dessas pessoas que trabalham com condições instáveis e inseguras sob a supervisão do Estado, mas não recebem mérito devido ao legado de exploração deixado pela escravidão no Brasil. (Produção estudantil, grifo nosso)

"Articulando", "o que hoje é, já foi” e "estabelecer uma relação" são expressões que imprimem a intenção dos alunos de não apenas narrar um acontecimento como um fato no passado, mas sim como algo residual no presente. Essa perspectiva vai ao encontro de Seffner e Pereira, pois, para eles, “o caráter ético do ensino de história está justamente no processo de construção de si mesmo como sujeito de um olhar, como subjetividade marcada por se permitir realizar uma determinada interpretação do passado e, ao mesmo tempo, do seu lugar no presente" (SEFFNER e PEREIRA, 2018, p. 20). Assim, percebe-se que a interpretação dos passados pelos estudantes tem como intenção responder a questões postas em nosso tempo como as desigualdades de gênero, o racismo e a reparação histórica por partes de sujeitos, e seus familiares, que foram apartados da sociedade pelo Estado, como é o caso dos hospitais-colônia para vítimas da hanseníase.

Dosse (2015) entende que o presente é uma construção no tempo, bem como está conectado a uma temporalidade de longa duração. A História do Tempo Presente não é definida apenas por abordar acontecimentos recentes. $\mathrm{Na}$ verdade, para o autor, trata-se de uma nova operação historiográfica. Nos últimos anos, segundo Dosse (2015), há na historiografia um interesse próprio pela memória e pelo patrimônio, justamente por entender que o presente é permeado por sentidos, principalmente porque o passado tem sido uma presença mais intensa no espaço público. Este é um dado fundamental ao pensar 
que o tema de memória e patrimônio é a abordagem mais presente nas edições do festival. Ao fazer essa opção, os estudantes não separam o presente do passado, algo essencial para pensar sobre tempo presente.

Outro ponto proposto pelo historiador francês sobre a categoria de tempo presente é a de um passado que ainda é contemporâneo. Nesse sentido, evocar a luta das mulheres do século XIX para o debate sobre a interrupção da fala de mulheres, assim como olhar para a história de vida de lixeiros e varredores de rua em perspectiva comparada com a escravidão africana, é perceber que os estudantes identificam no presente resíduos de outros contextos.

A discussão aqui enfrentada propõe que toda a cultura escolar seja integrada a seu tempo, e não como ilha isolada no presente. A escola está inserida em uma temporalidade. Henry Rousso (2016) é categórico ao propor que se pense o tempo presente como permeado pelo apetite do grande público pela História, no qual o cinema, a televisão, os suportes online - e acrescentamos que as redes sociais também têm parte nisso - têm discutido, divulgado e promovido usos dos passados.

Uma parte importante do pensamento de Rousso (2016), para a noção de temas sensíveis operada neste artigo, é a distinção entre uma resposta dada para acontecimentos imediatos e a análise desses acontecimentos postos em uma espessura temporal que se explica no recuo a um passado, que não se compreende tão rapidamente:

Como toda boa história, trata-se de restituir uma genealogia, de inserir o acontecimento em uma duração, de propor uma ordem de inteligibilidade que tenta escapar à emoção do instante, ou, para usar um vocabulário lacaniano, que tenta instituir um pouco de simbólico onde o imaginário invadiu tudo: é uma das tarefas essenciais da história, e uma das missões mais importantes da história do tempo presente. (ROUSSO, 2016, p. 237)

Um outro desafio posto por Rousso (2016) aos estudos sobre tempo presente é o fato de haver testemunhas vivas. Os estudos sobre passados em que os personagens já saíram de cena são vistos como diferentes das pesquisas acerca de um passado recente, do qual ainda há testemunhas. Inevitavelmente, haverá interpelações das pautas do tempo presente, socialmente vivas, no ensino de História quando se passa a considerar que o relato pode ser um importante meio para a aprendizagem histórica. 
Não nos debruçaremos sobre a relação entre testemunho e História, tema muito caro à História do tempo presente. Entretanto, destacamos que o recurso testemunhal percebe-se como uma rica fonte para o ensino de História, quando se quer construir um tema sensível. Essa relação testemunhal está posta em Seffner e Pereira (2018), quando analisam as narrativas dos alunos sobre episódios de racismo enfrentado por eles em uma aula sobre escravidão, assim como em Gil e Eugenio (2018), ao discutirem a prática de uma docente que incorporou testemunhos de migrantes haitianos para discutir as migrações/racismo na História do Brasil.

Sendo assim, concordamos com a argumentação de Seffner e Pereira sobre a aula de História ser um lugar em que "alguém chore, que alguém se espante, que alguém ache um absurdo, que alguém diga 'professor, o senhor não tem o direito de nos mostrar isso que está nos mostrando! O senhor não tem o direito, é muito forte, é muito pesado!'” (SEFFNER, PEREIRA, 2018, p. 23). Parece-nos que os testemunhos orais são caminhos possíveis para sensibilização. Exploraremos esses caminhos na próxima seção, pois percebemos que, ao construir suas temáticas, os alunos produtores dos curtas aqui analisados utilizam testemunhos para compor um quadro de sensibilização.

O caráter testemunhal do relato oral expõe um desafio aos professores de História ao se encarar que, em alguns cenários do passado, há atores que ainda não saíram de cena, estão vivos. Desse modo, a questão testemunhal pode ser vista de duas maneiras. A primeira é a própria seleção feita previamente pelo docente - trechos de livros, vídeos, documentários -, e a segunda é a reação de estudantes aos testemunhos trazidos pelos docentes - concordar, discordar, emocionar-se, ficar em silêncio. Acreditamos que o potencial sensível aparece quando esses relatos testemunhais podem se encontrar e tornar a aprendizagem histórica significativa ao promover a escuta e a alteridade. Portanto, percebemos que os estudantes têm essa intenção ao trazer no centro de suas produções as vivências testemunhais desses atores que são atravessadas por um passado que não passa.

As formas como os cadernos de pesquisa dos alunos são estruturados dão pistas sobre como mobilizaram o não contemporâneo no presente. No caso dos trabalhadores urbanos, eles narram a partir de alguns temas, como: escravizados mantidos pelo Estado na Colônia e no Império, da abolição da escravidão e as reformas urbanas nas primeiras décadas da República. Ao finalizar 
a pesquisa discutem que esses trabalhadores hoje, funcionários que prestam serviço ao Estado, são em sua maioria negros e vivem em bairros afastados da cidade de Itu. Na construção da narrativa, fica evidente que alguns conteúdos previstos nos temas clássicos do ensino de História são identificáveis, o que chama atenção, pois se veem alunos utilizando sua bagagem para discutir um tema presente. O passado tem mais espaço do que uma discussão sobre as condições de trabalho dos sujeitos analisados.

As estudantes que produziram a pesquisa sobre a desvalorização do discurso feminino usam uma estrutura em que o presente ocupa muito mais espaço do que o não contemporâneo. Elas usam como exemplos a entrevista de Manuela d'Ávila, o filme Eu Não Sou Um Homem Fácil, de Éléonore Pourriat, assim como expressões que designam práticas machistas, como manterrupting. Em seguida, elas abrem uma seção para mostrar como mulheres se articularam contra o patriarcado, elegendo o século XIX como as primeiras conquistas, citando a Inglaterra e os Estados Unidos como lugares pioneiros da Primeira Onda Feminista. Na questão dos séculos XX e XXI, as autoras escolhem sete mulheres que seriam símbolos dessa luta, sendo Bertha Lutz a primeira citada, e Maria da Penha e Dilma Rousseff, as duas últimas. A pesquisa aponta para uma história das mulheres, ou seja, agentes de sua história, e não apenas vítimas de um machismo que ecoa no presente.

No caso do Hospital-colônia do Pirapitingui, o grupo optou por uma lógica que discute a doença, o hospital, os funcionários, os pacientes e uma seção que eles chamam de dias atuais. "Devido ao tabu existente em volta da hanseníase, muito preconceito ainda acontecia nas imediações do hospital, envolvendo desde agressão a pacientes até mesmo roubo do apoio monetário que os moradores recebiam do governo.": esse trecho é um exemplo de que a proposta dos estudantes foi de construir a relação entre a doença e a criação do hospital por parte do Estado. Um fator interessante é que, diferente dos trabalhos citados anteriormente, não há usos evidentes de temas clássicos em ensino de História.

Ainda sobre as narrativas, percebe-se os usos de produções fílmicas, música e o patrimônio como relevantes na estrutura da pesquisa, fazendo-nos pensar o quanto as produções culturais do presente, desde 1980, vêm tendo o passado como um objeto privilegiado. Huyssen (2000) diz ser possível estabelecer uma relação entre memória e o tempo presente pela mudança na tempo- 
ralidade de nossas vidas "provocada pela complexa intersecção de mudança tecnológica, mídia de massa e novos padrões de consumo" (HUYSEN, 2000, p. 25). Assim, ele marca o nosso tempo como o da cultura da memória em que o passado é presente. A ideia de um passado presente vem da observação de que não mais se pensa do presente para um futuro, mas sim de um presente para um passado. As atrocidades e as violações de direitos humanos do século $\mathrm{XX}$ tornaram o futuro algo incerto, pois a promessa de progresso desenvolvida no projeto iluminista materializou-se em catástrofes que ainda ressoam em nosso tempo, seja pelas construções memoriais, seja pela não reparação jurídica de violências cometidas pelo Estado. Huyssen desenvolve essa ideia em duas obras, ${ }^{9}$ e nos cabe aqui apontar o quanto o ensino de História é atravessado por esse passado presente tendo os alunos como porta de entrada. As renovações nos temas a serem ensinados não ocorrem na mesma velocidade em que se dão as transformações culturais - e o FEC é um bom exemplo de como é necessário pensar nessa confluência entre o contexto dos jovens e o ensinar História.

Portanto, assumir que a História trata também de lidar com os vivos é de suma importância. Não só com sujeitos testemunhais de violações de direitos humanos, mas também com quem está em diálogo, sejam discentes em aulas, sejam espectadores de um curta-metragem. E aqui mora um elemento enfrentado pela História do tempo presente, que é assumir que as temporalidades são permeadas de visões distintas sobre acontecimentos, longe de apaziguamentos.

\section{OS CURTAS-DOCUMENTÁRIO EM QUESTÃO: CRIAÇÃO DE MUNDOS E SUGESTÕES PARA UMA NOVA PARTILHA DO SENSÍVEL}

A partir das discussões trazidas na seção anterior, gostaríamos de pensar a relação entre as temporalidades históricas e a produção dos curtas como construção de temas sensíveis. Diante deles, não podemos deixar de pensar como estudantes envolvem, desafiam e propõem realidades possíveis. Como quer Cezar Migliorin (2015), ${ }^{10}$ a criação de imagens fílmicas nas escolas possibilita outro regime de relação com o conhecimento, que passa necessariamente por uma reflexão crítica e uma postura criativa: 
Entender a rua, o bairro, o vizinho e a cidade com o cinema é entrar em uma relação com o outro e, simultaneamente, em uma atividade crítica e criativa - do plano, do quadro, da luz, do ritmo. Em outras palavras, aproximar os estudantes do que o mundo tem a nos dar e, simultaneamente, permitir que eles criem e inventem com esse mundo. [...] A aposta no cinema não deixa de ser um embate pela possibilidade de uma experiência, pela possibilidade da presença dos estudantes na relação com o que eles vêm e sentem. (MIGLIORIN, 2015, p. 10)

Da pesquisa, da relação com o outro, com os personagens do passado e com esses que habitam seus cotidianos - os vizinhos, as famílias, os comerciantes, os trabalhadores ou mesmo os professores da escola -, os alunos tecem uma relação com as temporalidades históricas e propõem uma alternativa diante dos impasses e desacertos identificados.

De acordo com Jacques Rancière (2009), podemos pensar na dimensão do "sensível" como o próprio mundo que habitamos e os lugares que ocupamos nele, que ao mesmo tempo autoriza e desautoriza certas formas de ser, fazer e dizer: aqui está a noção que, grosso modo, o filósofo denomina de “partilha do sensível”. A partilha não diz respeito ao compartilhamento, mas às atribuições das partes aos sujeitos. À ordem que determina os lugares dos corpos nessa partilha do sensível, Rancière vai denominar de "polícia", e é em oposição a ela que a categoria de "política" ganha força:

Aquela atividade [a política] em que rompe a configuração sensível em que as "partes" e as partes ou sua ausência são definidas com base em um pressuposto que, por definição, não tem lugar: a de uma parte dos que não têm parte. Essa ruptura se manifesta por uma série de atos que reconfiguram o espaço no qual as "partes", as partes e as ausências de partes se definiam. A atividade política é a que desloca um corpo do lugar que lhe era designado ou muda a destinação de um lugar; ela faz ver o que não cabia ser visto, faz ouvir um discurso ali onde só tinha lugar o ruído, faz ouvir como discurso o que só era ouvido como ruído. (RANCIÈRE, 2018, p. 43)

Quer dizer, a noção de política em Rancière está ligada à ideia de fissura na partilha do sensível, a uma postura humana que desafia a ordem policial ao verificar a igualdade do seu corpo em relação aos outros.

A partir dessa breve explicação, queremos evidenciar que, se por um lado 
fazer filmes na escola implica uma relação crítica e criativa com a comunidade dentro da qual os estudantes estão inseridos, por outro, eles estão mobilizando temas prementes em nosso tempo para sugerir outra - necessária e urgente partilha do sensível. Como nos lembra Comolli (2012, p. 560), "filmar é dar ao que é filmado uma certa forma de existência, uma certa intensidade de ser: no mais estrito senso, realizar o gesto criador". Portanto, uma das características das produções estudantis, inerente às imagens no cinema, é que eles estão produzindo uma relação dialética com o mundo, em suas dimensões espacial e temporal. A partir disso, lançaremos nosso olhar aos curtas, suas temáticas e ao modo como foram concebidos.

O curta Olha quem fala! aborda como mulheres têm suas falas constante e historicamente interrompidas pelos homens, seja nos espaços político-institucionais, doméstico, profissional etc. O filme consiste em uma seleção de vídeos encontrados na internet (que mostram situações de interrupção feminina) que são intercalados a falas de mulheres da comunidade escolar e especialistas no tema. O filme é introduzido pela música "O que se cala", ${ }^{11}$ interpretada pela cantora Elza Soares, e ouvimos: "mil nações moldaram minha cara, minha voz uso pra dizer o que se cala, o meu país é meu lugar de fala". Na sequência, vemos uma provocação a respeito do termo manterrupting, com a seguinte frase: "você pode não saber o que significa essa palavra, mas com certeza já presenciou ou vivenciou uma situação em que ela se aplicaria”.

O filme é concluído com a seguinte fala de Marielle Franco, na tribuna da Câmara Municipal do Rio de Janeiro: "não serei interrompida. Não aturo interrompimento dos vereadores dessa casa. Não aturarei de um cidadão que vem aqui e não sabe ouvir a posição de uma mulher eleita". Tal fala foi proferida no dia 8 de março de 2018. No dia 14 de março daquele mesmo mês e ano, Marielle foi brutalmente assassinada. O curta Olha quem fala! também é de 2018 e, certamente, a comoção da morte tem impacto sobre as discussões que evoca. Em seus (aparentemente) breves dez minutos, vemos uma realidade fílmica em que nenhuma mulher é interrompida, justificando, inclusive, o seu próprio título.

A dimensão abordada acima também pode ser percebida nos filmes Marcados e Trabalhadores, invisibilidade urbana, com as particularidades de cada grupo e seus respectivos temas. No primeiro, vemos a história do Hospital Dr. Francisco Ribeiro Arantes, também conhecido como colônia-asilo de Pirapi- 
tingui, na cidade de Itu. Mais do que contar a história do hospital, o objetivo é apresentar as histórias dos pacientes, tanto do passado quanto do presente, cujas dores se solidifica(ra)m nesse que é hoje um patrimônio tombado. Os créditos introdutórios são acompanhados de uma música instrumental à medida que vemos o caminho até hospital. Os alunos optaram por inserir, logo no início, uma entrevista, realizada com um médico, a respeito da doença. Ele nos informa que as colônias de leprosários surgiram no início do século XX, menos como proposta de cuidado dos doentes e mais como uma forma de apartá-los da sociedade. Excertos da entrevista com uma atual paciente são inseridos ao longo da trama, que nos revela as dores da estigmatização e as piores marcas da doença - as que não estão na pele -, e seus impulsos para continuar a existir.

Para dimensionar o passado em imagens, os alunos recorrem ao documentário "Lepra: espetáculo do medo", ${ }^{12}$ dirigido por Ítalo Tronca, professor da Universidade Estadual de Campinas (UNICAMP). Os estudantes abordam como filhos eram separados dos pais acometidos pela hanseníase, aspecto reforçado na entrevista realizada com a professora Cristina Meneguello, também da UNICAMP, que estudou o processo de tombamento do referido hospital. Na década de 1940, lembra-nos a historiadora, quando já era conhecida a não hereditariedade da hanseníase, pais e filhos cresceram isolados, como se ambos fossem portadores de uma doença que justificaria seu total isolamento: os pais nas colônias e os filhos nos chamados "internatos". É difícil fazer uma descrição de Marcados em poucas linhas, tendo em vista a potência criadora dos estudantes, que recorreram a pacientes dos hospitais, especialistas, arquivos e uma emissora de televisão para criarem suas imagens. Tal descrição, no entanto, busca evocar que, a partir da noção de "partilha do sensível”, poderíamos dizer que aos pacientes foram determinados modos cerceados de estar no mundo, figurados pelos muros do hospital, pois construíram uma vida e uma dinâmica social dentro dele e fora da vida em comum. Inferimos, portanto, que Marcados é sobretudo um apelo para que essas pessoas sejam vistas, dadas a ver. Nos 10 minutos do filme eles também existem.

Algo semelhante acontece em Trabalhadores, invisibilidade urbana, como o próprio título sugere. $\mathrm{O}$ foco do curta está em visibilizar coletores de lixo da cidade de Itu, que habitam o cotidiano da cidade, mas são invisíveis àqueles que passam por eles. O filme é montado com entrevistas com os coletores, trabalhadores de outras áreas da empresa e especialistas do tema com o qual 
eles estabelecem uma relação: a questão da escravidão, sobretudo das pessoas escravizadas que ficaram conhecidas como "escravos da nação". O filme começa da seguinte maneira: os invisíveis se apresentam e, finalmente, os conhecemos. É importante lembrar que os filmes são disponibilizados à comunidade, escolar e extraescolar, em uma culminância de exibição. Vemos em seguida as entrevistas com especialistas sobre o tema da escravidão. Em nenhum momento é explicitada a relação entre "escravos da nação" e os catadores de lixo, mas a construção das imagens nos leva a inferi-la rapidamente. Os estudantes percebem a residualidade da escravidão, percebida na cor das pessoas que fazem serviços como o de limpar as ruas.

Em um certo momento, muito emocionada, uma trabalhadora entrevistada diz que, certa vez, uma criança correu em sua direção e disse ao abraçá-la: "sou seu fã". Ali, em uma combinação de lágrimas e risos, diz que se sentiu feliz por saber dessa admiração. Isso parece importante para quem está sendo invisibilizado ou estigmatizado: os trabalhadores contam que são constantemente chamados de "cheirosinhos" ou sentem outros tipos de discriminação ao entrarem nos ônibus, por exemplo.

Comum aos curtas Marcados e Trabalhadores, a invisibilidade urbana é que os estudantes se valem sobretudo de entrevistas para a criação das imagens, que parecem possibilitar o disparo de memórias que nos conduzem ao passado - estabelecendo o dinâmico caminho entre as temporalidades, que é parte central da compreensão desse texto. Analisando dois filmes de Eduardo Coutinho, Claudia Mesquita $(2016)^{13}$ sugere que as entrevistas realizadas pelo diretor, marca estética de seu cinema-documentário, concebem uma escrita da História preocupada em reconstituir os elos entre o presente e o "outrora". Associamos essa postura às entrevistas dos estudantes. Em 2019, inclusive, ano de realização dos curtas, os estudantes tiveram uma formação sobre a linguagem do documentário, cujos exemplos foram os filmes de Coutinho.

As entrevistas produzidas pelos alunos parecem ser um dos aspectos que aciona as residualidades do passado no presente. $\mathrm{Ou}$, dito de outra forma, elas disparam a retomada desses passados traumáticos a partir das dores e estigmas que ainda hoje acometem "partes" da população. As testemunhas vivas não se encerram em palavras, mas nas próprias existências daqueles que vemos: em seus gestos, vozes, enfim, em seus próprios corpos. Retomando uma ideia trazida na seção anterior, percebemos que tais testemunhos contribuem para a 
construção do tema sensível sob a forma de uma experiência pautada na possibilidade de sensibilização.

Os três curtas aqui citados, como já mencionamos, parecem questionar uma partilha do sensível, na qual mulheres, doentes e trabalhadores recebem determinadas formas de estar no mundo. Se é ela quem autoriza e desautoriza as formas que cada um deve ser, fazer e dizer, os curtas nos lembram que mulheres possuem o direito à fala tanto quanto os homens, os doentes devem ser capazes de estabelecer uma conexão com a sociedade tanto quanto os não-doentes, os catadores de lixo devem ser visíveis em suas profissões como são os outros trabalhadores. Destacamos a dimensão política nessas fissuras da partilha do sensível e nas sugestões de uma vida menos fragmentada, já que, como lembra Rancière (2018, p. 45), o único princípio da política - em sua acepção - é a igualdade.

\section{CONSIDERAÇÕES FINAIS}

Este artigo buscou contribuir com os estudos que tomam o presente, enquanto temporalidade, como fundamental para pensar a aula de História. Ana Maria Monteiro (2015) lembra-nos disso ao refletir sobre a inserção do professor na dinâmica do presente. Concordando com ela, mobilizamos aqui os conhecimentos teóricos desse campo, articulando as discussões historiográficas à produção dos curtas e ao enfrentamento das suas respectivas questões pelos estudantes.

Sendo assim, partimos da ideia de que os temas sensíveis são mediados por um presente, em que o passado representado, ou midiatizado, no espaço público contribui para o "peso" de alguns passados que se mostram não resolvidos e que doem. Geralmente, são temas mobilizados que não estão postos nas narrativas nacionais hegemônicas. Esse é um ponto interessante, pois ao analisar as referências usadas neste artigo na relação com os curtas-documentário do FEC, percebemos que os temas sensíveis são pontos de vista que a história nacional, por ser narrada de forma apaziguada e sem possibilidade para o conflito, oculta: fala-se de escravidão, mas não do racismo nos dias de hoje, por exemplo. Assim, os temas sensíveis parecem mobilizar o dissenso como pás que desenterram o que se quer na vala.

Com a noção de "partilha do sensível", buscamos compreender a ação dos estudantes e suas posturas diante dessa sociedade fraturada. Sem dúvidas, o 
que percebemos é uma ação crítica e propositiva de mundo, refletida na criação dos curtas-documentário. Como vimos em Rancière, a fissura na partilha do sensível pode ser compreendida como "política" e refere-se a uma atividade dos sujeitos ou, ainda, a um modo de subjetivação.

Gert Biesta (2012) propõe pensar a Educação a partir de três funções. A primeira é a qualificação e refere-se ao conjunto de conhecimentos necessários à realização de alguma coisa, como, por exemplo, uma prova. A segunda é a socialização, as normas e regras que precisam ser conhecidas para o convívio em sociedade, para além da própria escola. Por último, a subjetivação, que relaciona-se ao "tornar-se sujeito", ou seja, a percepção de que, embora estejam em uma sociedade pautada por regras e lugares definidos, os estudantes não são tábulas rasas e podem construir suas próprias visões sobre eles.

Diante disso, não podemos ignorar, e talvez seja esse um dos aspectos mais instigantes do FEC, que estudantes estão em forte envolvimento com os seus temas: pesquisando, realizando entrevistas, criando imagens, percebendo sua realidade a partir de perspectivas e posturas que vão se reformulando e ganhando forma com o próprio trabalho. Propomos, portanto, que, ao questionar as partes e as atribuições dos sujeitos na partilha do sensível, estão também refletindo sobre seus próprios lugares, suas próprias maneiras de "ser", "fazer” e "dizer”, ou seja, estão envolvidos em um processo de subjetivação. É, inclusive, sobre esse princípio que reside a concepção do festival: a necessidade de garantir a autonomia dos estudantes para que se reconheçam como sujeitos dentro de uma sociedade e de uma História.

Trazemos aqui um fator importante a se considerar nas pesquisas sobre ensinar História: os alunos. Por mais que haja projetos conservadores que busquem, em certa medida, controlar os temas a serem ensinados, devemos compreender os alunos como agentes autônomos que trazem no centro de suas criações assuntos que os atravessam enquanto sujeitos. Entendemos que há algo nesse presente, marcado por uma cultura da memória, que contribui para que os estudantes vejam o passado como forma de entender as dores que persistem em nosso tempo.

\section{REFERÊNCIAS}

BIESTA, Gert. Boa educação na era da mensuração. Cadernos de pesquisa, v. 42, n. 147, p. 808-825, 2012. 
COMOLLI, Jean-Louis. Corps et cadre. Cinema, éthique, politique. Lagrasse: Verdier, 2012.

DOSSE, François. História do Tempo Presente e Historiografia. Revista Tempo e Argumento. Florianópolis, v. 4, n. 1 p. 05-22, jan/jun. 2012.

FIORIN, José Luis. Teorias do discurso e ensino da leitura e da redação. Gragotá (UFF), Niterói, v. 2, p. 5-27, 1997.

GIL, Carmen; EUGENIO, Jonas. Ensino de história e temas sensíveis: abordagens teórico-metodológicas. Revista História Hoje, v. 7, nº 13, p. 139-159, 2018.

HUYSSEN, Andreas. Seduzidos pela Memória. Arquitetura, monumento, mídia. Rio de Janeiro,: Aeroplano Editora, 2000.

HUYSSEN, Andreas. Culturas do passado presente: modernismos, artes visuais, práticas da memória. Rio de Janeiro: Contraponto, 2014.

MONTEIRO, Ana Maria Ferreira da Costa. Aulas de História: questões do/no tempo presente. Educar em Revista, s/v, nº.58, p. 165-182, 2015.

MENEGUELLO, Cristina. Patrimônios difíceis (sombrios). In: CARVALHO, Cristina; MENEGUELO, Cristina (Orgs). Dicionário temático de patrimônio: Debates contemporâneos. Campinas: Editora Unicamp, 2020.

MESQUITA, Claudia. Entre agora e outrora: a escrita da história no cinema de Eduardo Coutinho. Galaxia (São Paulo), n. 31, p. 54-65, abr. 2016.

MIGLIORIN, CEZAR. Inevitavelmente cinema: educação, política e mafuá. Rio de Janeiro: Beco do Azougue, 2015.

RANCIÈRE, Jacques. A partilha do sensível. São Paulo: Editora 34, 2009.

RANCIĖRE, Jacques. O desentendimento. São Paulo: Editora 34, 2018.

ROCHA, Helenice. A presença do passado na aula de História. In: ROCHA, Helenice; MAGALHÃES, Marcelo (orgs.). Ensino de História: usos do passado, memória e mídia. Rio de Janeiro: FGV Editora, 2015.

ROUSSO, Henry. A última catástrofe: a história, o presente, o contemporâneo. Trad. Fernando Coelho e Fabrício Coelho. Rio de Janeiro: FGV, 2016.

SEFFNER, Fernando; PEREIRA, Nilton. Ensino de História: passados vivos e educação em questões sensíveis. Revista História Hoje, v. 7, n 13, p. 14-33, 2018.

\section{NOTAS}

${ }^{1}$ O presente trabalho foi realizado com apoio da Coordenação de Aperfeiçoamento de Pessoal de Nível Superior - Brasil (CAPES) - Código de Financiamento 001.

${ }^{2}$ Convidamos a todos e todas a assistirem aos filmes produzidos no Festival Estudantil de 
Curtas, sobretudo aqueles que se tornaram objeto de análise para este texto. Acreditamos que a experiência audiovisual, tal qual foi pensada pelos e pelas estudantes, pode contribuir com a leitura e a compreensão das reflexões que traçamos aqui. Os vídeos podem ser assistidos através do seguinte link: https://www.youtube.com/channel/UCujHsWM2Ri9K32H_ PgiCLkg. Os links para os curtas analisados serão inseridos nas notas, à medida que forem sendo mobilizados ao longo do texto.

${ }^{3}$ Dizer que alguns curtas seguem o tema proposto não os desqualifica. Afinal, todos os curtas precisam, em algum nível, partir de um tema-gerador. Segundo o linguista José Luiz Fiorin, os textos possuem dois percursos, combináveis ou não: o figurativo e o temático. No figurativo, o que vemos são percursos objetivos, enquanto no temático podemos perceber elementos que subjazem a estrutura das figuras apresentadas. Como exemplo: dentro do tema "se a história fosse nossa casa" vimos curtas vinculados à casa como cultura material ou arquitetura (figurativo); mas também vimos curtas que abordam temas que extrapolam a História como passado e a própria casa: são os curtas que nutrem-se do tema central proposto para abordar outras questões (do tempo presente), como gênero e relações étnico-raciais. Utilizamos essa referência como metodologia para classificação dos curtas que transcendem ou não o tema central.

${ }^{4} \mathrm{O}$ curta-metragem não está disponível na página do projeto por não ter sido aprovado pela direção do Hospital Dr. Francisco Ribeiro Arantes para acesso do público em geral, mas apenas para fins pedagógicos. Diante de qualquer interesse é possível entrar em contato com os responsáveis do festival, através do seguinte e-mail: curtasmonteirolobato@ gmail.com.

${ }^{5}$ As pesquisas que tomam os hospitais-colônia como objeto têm ganhado força nas últimas décadas em detrimento de outras modalidades de patrimônio. Cristina Meneguello (2020), no verbete Patrimônio Difícil, para o Dicionário Temático do Patrimônio, aponta que os hospitais-colônia são exemplos deste patrimônio, pois trazem tensões morais, assim como atestam o sofrimento, a segregação; permanecendo como uma lembrança incômoda.

${ }^{6} \mathrm{O}$ curta pode ser acessado através do seguinte link: https://www.youtube.com/watch?v $=\mathrm{HJbXBp} 7 \mathrm{dL} 30$

7 O curta pode ser acessado através do seguinte link: https://www.youtube.com/ watch? $\mathrm{v}=\mathrm{Ir} 68 \mathrm{Fp} 5 \mathrm{mlFY} \& \mathrm{t}=3 \mathrm{~s}$

${ }^{8}$ Compreendemos a linguagem científica tal como Helenice Rocha (2016): aquela que tem como objetivo superar inexatidões da linguagem cotidiana e, para isso, responde à necessidade de formalizações. Em seu texto, Rocha discute tal formalização com o próprio conhecimento histórico.

${ }^{9}$ Os livros são intitulados "Seduzidos pela memória: arquitetura, monumentos, mídia" (2000) e "Culturas do passado-presente: modernismos, artes-visuais, políticas de memória" (2014).

${ }^{10}$ Migliorin defende que o "fazer cinema" nas escolas não passa, necessariamente, por um aprendizado da linguagem cinematográfica ou a incorporação de um conjunto de técnicas, 
mas sobretudo pela experiência de contar uma percepção da comunidade e do mundo através das imagens. Os estudantes passam por diversas formações, inclusive sobre teoria e linguagem cinematográfica, mas afirmamos que eles estão fazendo cinema porque incluem a relação com a comunidade e a subjetividade da qual nos fala Migliorin. Ver: MIGLIORIN, Cezar. Inevitavelmente cinema: educação, política e mafuá. Rio de Janeiro: Beco do Azougue, 2015.

${ }^{11}$ A música foi lançada em 2018, mesmo ano de produção do curta.

${ }^{12}$ O documentário é de 1987.

${ }^{13}$ A autora parte de uma compreensão da História a partir de Walter Benjamin, onde a temporalidade histórica não é compreendida de modo unilateral: o presente ilumina o passado e, iluminado, torna-se força no presente. Essa dimensão da História possui proximidade com o modo como estamos entendendo sua temporalidade nesse texto. Os filmes em questão são "Cabra marcado para morrer" (1984) e "Peões" (2004).

Artigo recebido em 27 de agosto de 2020. Aprovado em 08 de outubro de 2020. 